\title{
KORELASI CPT DAN SPT TERHADAP KUAT GESER TANAH DALAM MENENTUKAN DAYA DUKUNG TANAH
}

\author{
Julita Silitonga ${ }^{1}$, Mohammad Ikhwan Yani ${ }^{2}$, dan ir. Suradji Gandi M.M³ \\ ${ }^{123}$ Program Studi Teknik Sipil, Fakultas Teknik, Universitas Palangka Raya, \\ E-mail: julitasilitonga51@ gmail.com ${ }^{1}$, m.ikhwanyani@eng.upr.ac.id ${ }^{2}$, dan \\ suradjigandi_ir@jts.upr.ac.id. \\ $/$ HP.+6282256005446 ${ }^{1}$
}

\begin{abstract}
ABSTRAK
Tanah mempunyai peranan penting dalam ilmu konstruksi yang berfungsi untuk menyokong pondasi dari bangunan dan memiliki nilai daya dukung tanah. Penelitian ini bertujuan untuk mengetahui sifat fisik dan mekanis tanah, mengetahui nilai CPT dan N-SPT, mengetahui nilai daya dukung tanah dari hasil korelasi antara CPT, N-SPT di lapangan terhadap kuat geser dari hasil pemeriksaan laboratorium di lokasi pembangunan Gedung Pusat Pembangunan IPTEK dan Inovasi Gambut di Universitas Palangka Raya Kalimantan Tengah. Hasil pengujian sifat fisik tanah diperoleh klasifikasi tanah menurut USCS tanah gambut sebagai kelompok PT, tanah pasir sebagai kelompok SP, tanah lempung sebagai OL sedangkan menurut AASHTO tanah gambut sebagai kelompok A-3, tanah lempung sebagai kelompok A-7-5 (13). Hasil pengujian sifat mekanik tanah gambut $(\tau)=0,096 \mathrm{~kg} / \mathrm{cm}^{2}$, tanah pasir $(\tau)=0,200 \mathrm{~kg} / \mathrm{cm}^{2}$, tanah lempung $(\tau)=$ $0,230 \mathrm{~kg} / \mathrm{cm}^{2}$. Pemeriksaan CPT berdasarkan nilai FR kedalaman 0,0 m-5,8 m nilai tekanan konus (qc) $180 \mathrm{~kg} / \mathrm{cm}^{2}$. Pemeriksaan SPT kedalaman $0 \mathrm{~m}-30 \mathrm{~m} \mathrm{~N}$ $\mathrm{SPT}=50$. Nilai daya dukung tanah dengan analisis korelasi CPT terhadap Kuat Geser tanah gambut Qult= 3,4064 kg/ $\mathrm{cm}^{2}$; Qijin= 1,135 kg/cm ${ }^{2}$, tanah lempung

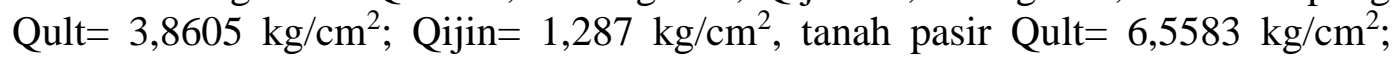
Qijin $=2,410 \mathrm{~kg} / \mathrm{cm}^{2}$ sedangkan nilai daya dukung tanah dengan analisis korelasi SPT terhadap Kuat Geser tanah gambut Qult $=5,7586 \mathrm{~kg} / \mathrm{cm}^{2}$; Qijin= 1,920 $\mathrm{kg} / \mathrm{cm}^{2}$, tanah lempung Qult $=7,9560 \mathrm{~kg} / \mathrm{cm}^{2}$; Qijin $=2,652 \mathrm{~kg} / \mathrm{cm}^{2}$, tanah pasir Qult $=13,8148 \mathrm{~kg} / \mathrm{cm}^{2}$; Qijin $=4,605 \mathrm{~kg} / \mathrm{cm}^{2}$.
\end{abstract}

Kata kunci : Tanah, SPT, CPT, Kuat Geser, Analisis Korelasi.

\section{ABSTRACT}

Soil has an important role in the science of construction that serves to support the foundation of the building and has the value of land carrying capacity. This study aims to know the physical and mechanical properties of soil, know the value of $C P T$ and N-SPT, know the value of soil carrying capacity from the correlation between CPT, N-SPT in the field against the shear strength of the results of laboratory tests at the construction site of the Center for Science and Technology 
Development and Peat Innovation at the University of Palangka Raya Central Kalimantan. The results of soil physical properties test obtained soil classification according to USCS peat soil as PT group, sand soil as SP group, clay soil as OL while according to AASHTO peat soil as A-3 group, clay soil as A-7-5 group (13). Test results of the mechanical properties of peat soil $(\tau)=0.096 \mathrm{~kg} / \mathrm{cm} 2$, sand soil $(\tau)=0.200 \mathrm{~kg} / \mathrm{cm} 2$, clay soil $(\tau)=0.230 \mathrm{~kg} / \mathrm{cm} 2$. CPT inspection based on $R F$ depth value $0.0 \mathrm{~m}-5.8 \mathrm{~m}$ pressure value konus (qc) $180 \mathrm{~kg} / \mathrm{cm} 2 . S P T$ inspection depth $0 \mathrm{~m}-30 \mathrm{~m} \mathrm{~N}-\mathrm{SPT}=50$. Soil carrying capacity value with CPT correlation analysis to Qult peat soil shear strength=3.4064 kg/cm2; Qijin= 1,135 kg/cm2, Qult clay= $3.8605 \mathrm{~kg} / \mathrm{cm} 2 ;$ Qijin $=1,287 \mathrm{~kg} / \mathrm{cm} 2$, Qult sand soil $=6.5583 \mathrm{~kg} / \mathrm{cm} 2$; Qijin $=2,410 \mathrm{~kg} / \mathrm{cm} 2$ while the value of soil carrying capacity with analysis of SPT correlation to Qult peat soil shear strength $=5.7586 \mathrm{~kg} / \mathrm{cm} 2 ;$ Qijin $=1,920$ $\mathrm{kg} / \mathrm{cm} 2$, Qult clay= $7.9560 \mathrm{~kg} / \mathrm{cm} 2 ;$ Qijin $=2,652 \mathrm{~kg} / \mathrm{cm} 2$, Qult sand soil= $13.8148 \mathrm{~kg} / \mathrm{cm} 2 ;$ Qijin $=4,605 \mathrm{~kg} / \mathrm{cm} 2$.

Keywords : Soil, SPT, CPT, Strong Shear, Correlation Analysis.

\section{PENDAHULUAN}

Dalam tahap pembangunan suatu struktur bangunan daya dukung tanah perlu diketahui untuk menghitung dan merencanakan dimensi pondasi yang dapat mendukung beban struktur yang akan dibangun. Untuk mengetahui daya dukung tanah perlu dilakukan penyelidikan tanah dengan cara uji lapangan dan uji laboratorium. Alat yang diperlukan dalam penyelidikan tanah di lapangan seperti CPT, SPT, dan alat-alat pengujian pada laboratorium. Hasil pengujian CPT dan SPT yang didapat dari lapangan akan dipergunakan untuk memperoleh hasil analisis daya dukung tanah. Hasil pengujian CPT diperoleh dari pembacaan manometer akibat perlawanan konus dengan gesekan lapisan tanah dengan nilai konus dalam satuan $\mathrm{Kg} / \mathrm{cm}^{2}$. Hasil pengujian SPT diperoleh dari pemukulan tabung belah dinding tebal ke dalam tanah, disertai pengukuran jumlah pukulan untuk memasukkan tabung belah sedalam $300 \mathrm{~mm}$ vertikal. Dalam sistem beban jatuh ini digunakan palu dengan berat $63,5 \mathrm{~kg}$ yang dijatuhkan secara berulang dengan tinggi jatuh $0,76 \mathrm{~m}$. Pelaksanaan pengujian dibagi dalam tiga tahap, berturut-turut setebal $150 \mathrm{~mm}$ untuk masing-masing tahap. Tahap pertama dicatat sebagai dudukan,sementara tahap ke-dua dan ke-tiga dijumlahkan untuk Imemperoleh nilai pukulan N atau perlawanan SPT (dinyatakan dalam pukulan / 0,3 m). Pengujian CPT, SPT ini berlokasi di sekitar pembangunan Gedung Pusat Pengembangan IPTEK dan Inovasi Gambut di Universitas Palangka Raya Provinsi Kalimantan Tengah.

\section{Tujuan Penelitian}

Adapun tujuan dari penelitian ini:

1. Mengetahui sifat fisik dan sifat mekanis tanah di lokasi pembangunan Gedung Pusat Pengembangan IPTEK dan Inovasi Gambut di Universitas Palangka Raya, Kalimantan Tengah.

2. Mengetahui nilai CPT dan nilai N-SPT di lokasi pembangunan Gedung Pusat Pengembangan IPTEK dan Inovasi Gambut di Universitas Palangka Raya, Kalimantan Tengah. 
3. Mengetahui nilai daya dukung tanah dari hasil korelasi antara CPT terhadap kuat geser dan SPT terhadap kuat geser pada lokasi pembangunan Gedung Pusat Pengembangan IPTEK dan Inovasi Gambut di Universitas Palangka Raya, Kalimantan Tengah.

\section{TINJAUAN PUSTAKA}

\section{Tanah}

Tanah adalah kumpulan (agregat) butiran mineral alami yang bisa dipisahkan oleh suatu cara mekanik jika agregat tersebut diaduk dalam air. Sistem klasifikasi tanah adalah suatu system beberapa jenis tanah yang berbeda-beda tetapi mempunyai sifat yang serupa kedalam kelompok-kelompok berdasarkan pemakaiannya. Sistem klasifikasi memberikan suatu bahasa yang mudah untuk menjelaskan secara singkat sifat-sifat umum tanah yang sangat bervariasi tanpa penjelasan yang terinci.

Tabel 1. Batasan-batasan Uukuran Golongan Tanah Nama golongan Ukuran Butiran Tanah (mm)

\begin{tabular}{|c|c|c|c|c|}
\hline \multirow[t]{2}{*}{ Nama golongan } & \multicolumn{4}{|c|}{ Ukuran Butiran Tanah (mm) } \\
\hline & Kerikil & Pasir & Lanau & lempun \\
\hline $\begin{array}{l}\text { Massachusetts Institute of } \\
\text { Technology }\end{array}$ & $>2$ & $2-0,06$ & $0,06-0,002$ & $\begin{array}{c}\mathbf{g} \\
<0,002\end{array}$ \\
\hline $\begin{array}{l}\text { U.S. Department of } \\
\text { Agriculture (USDA) }\end{array}$ & $>2$ & $2-0,05$ & $0,05-0,002$ & $<0,002$ \\
\hline $\begin{array}{l}\text { American Association of State } \\
\text { Higway and Transpotation Officals } \\
\text { (AASHTO) }\end{array}$ & $76,2-2$ & $2-0,075$ & $\begin{array}{l}0,075- \\
0,002\end{array}$ & $<0,002$ \\
\hline $\begin{array}{l}\text { Unified Soil Classifacition System } \\
\text { (U.S Army Corps of Engineers, U.S. } \\
\text { Bureau of Reclamation) }\end{array}$ & $\begin{array}{l}76,2- \\
4,75\end{array}$ & $\begin{array}{l}4,75- \\
0,075\end{array}$ & $<0,0075$ & $\begin{array}{c}<0,007 \\
5\end{array}$ \\
\hline
\end{tabular}

\section{Klasifikasi Tanah}

Sistem klasifikasi AASHTO Sistem ini membagi tanah ke dalam 7 kelompok utama yaitu A-1 sampai dengan A-7. Tanah yang diklasifikasikan ke dalam A-1, A-2, dan A-3 adalah tanah berbutir di mana $35 \%$ atau kurang dari jumlah butiran tanah tersebut lolos ayakan No. 200. Tanah di mana lebih dari $35 \%$ butirannya tanah lolos ayakan No. 200 diklasifikasikan ke dalam kelompok A-4, A-5 A6, dan A-7. Sedangkan Sistem klasifikasi USCS memiliki dua kategori yaitu Tanah berbutir kasar (coarse-grained soils) yang terdiri atas kerikil dan pasir yang mana kurang dari 50\% tanah yang lolos saringan No. 200 (F200< 50). Simbol kelompok diawali dengan $\mathrm{G}$ untuk kerikil (gravel) atau tanah berkerikil (gravelly soil) atau $\mathrm{S}$ untuk pasir (sand) atau tanah berpasir (sandy soil). Tanah berbutir halus (fine-grained soils) yang mana lebih dari 50\% tanah lolos saringan No. 200 (F200 $\geq 50)$. 


\section{Pemeriksaan Kuat Geser Langsung (Direct Shear)}

Uji geser langsung merupakan pengujian parameter kuat geser tanah yang paling mudah dan sederhana. Kekuatan geser tanah dapat didefinisikan sebagai kemampuan maksimum tanah untuk bertahan terhadap usaha perubahan bentuk pada kondisi tekanan dan kelembapan tertentu. Pemeriksaan ini bertujuan untuk menentukan kohesi (c) dan sudut geser dalam $(\phi)$.

\section{Analisis Hasil Korelasi}

Analisis data hasil pengujian akan diperoleh dengan mencari hubungan satu sama lain (korelasi) menggunakan regresi linear sederhana atau menggunakan regresi yang paling sesuai untuk mendapatkan hubungan antara hasil uji CPT, hasil uji SPT, dengan hasil uji laboratorium.

\section{Cone Penetration Test (CPT)}

Pemeriksaan ini dimaksudkan untuk mengetahui perlawanan penetrasi konus dan hambatan lekat tanah. perlawanan penetrasi konus adalah perlawanan tanah terhadap ujung konus yang dinyatakan dalam gaya persatuan luas. Hambatan lekat adalah perlawanan geser tanah terhadap selubung bikonus dalam gaya persatuan panjang.

\section{Standart Penetration Test (SPT)}

Uji SPT terdiri atas uji pemukulan tabung belah dinding tebal ke dalam tanah, disertai pengukuran jumlah pukulan untuk memasukkan tabung belah sedalam $300 \mathrm{~mm}$ vertikal. Dalam sistem beban jatuh ini digunakan palu dengan berat 63,5 $\mathrm{kg}$, yang dijatuhkan secara berulang dengan tinggi jatuh $0,76 \mathrm{~m}$. Pelaksanaan pengujian dibagi dalam tiga tahap, yaitu berturut-turut setebal $150 \mathrm{~mm}$ untuk masing-masing tahap. Tahap pertama dicatat sebagai dudukan, sementara tahap ke-dua dan ke-tiga dijumlahkan untuk memperoleh nilai pukulan $\mathrm{N}$ atau perlawanan SPT.

\section{Daya Dukung Tanah}

Daya dukung tanah (bearing capacity) adalah kekuatan tanah untuk menahan suatu beban yang bekerja pada tanah yang biasanya disalurkan melalui pondasi. Daya dukung tanah batas $\left(\mathrm{q}_{\mathrm{u}}=\mathrm{q}_{\mathrm{ult}}=\right.$ ultimate bearing capacity $)$ adalah tekanan maksimum yang dapat diterima oleh tanah akibat beban yang bekerja tanpa menimbulkan kelongsoran geser pada tanah pendukung tepat dibawah dan sekeliling pondasi. Pada perhitungan Daya Dukung Tanah ini akan dilakukan menurut teori Terzaghi.

\section{METODE PENELITIAN}

\section{Lokasi Penelitian}

Penelitian ini menggunakan sampel tanah dan data Pengujian CPT, SPT berasal dari sekitar pembangunan Gedung Pusat Pengembangan IPTEK dan Inovasi Gambut di Universitas Palangka Raya Provinsi Kalimantan Tengah

\section{Metode Pengambilan Sampel}

Pada penelitian ini data primer berupa penyelidikan tanah untuk pengambilan sampel tanah yang akan diuji di laboratorium. Sampel tanah yang diambil adalah 
tanah tidak terganggu (Undisturbed Soil) dan tanah terganggu (Disturbed Soil) menggunakan Hand Boring. Pengujian sifat-sifat fisik tanah di laboratorium yang mencakup pemeriksaan Kadar Air; Berat Volume; Berat Jenis; Batas-batas Atterberg; Analisa Saringan; Hydrometer dan sifat mekanik mencakup pemeriksaan Kuat Geser Langsung sedangkan Data sekunder merupakan sumber data yang tidak langsung memberikan data dimana data yang diperoleh dari pihak instansi, atau berbentuk dokumen. Data sekunder penelitian ini berupa hasil penyelidikan CPT, SPT dari pihak instansi yang terkait, yaitu data yang akan digunakan untuk penelitian.

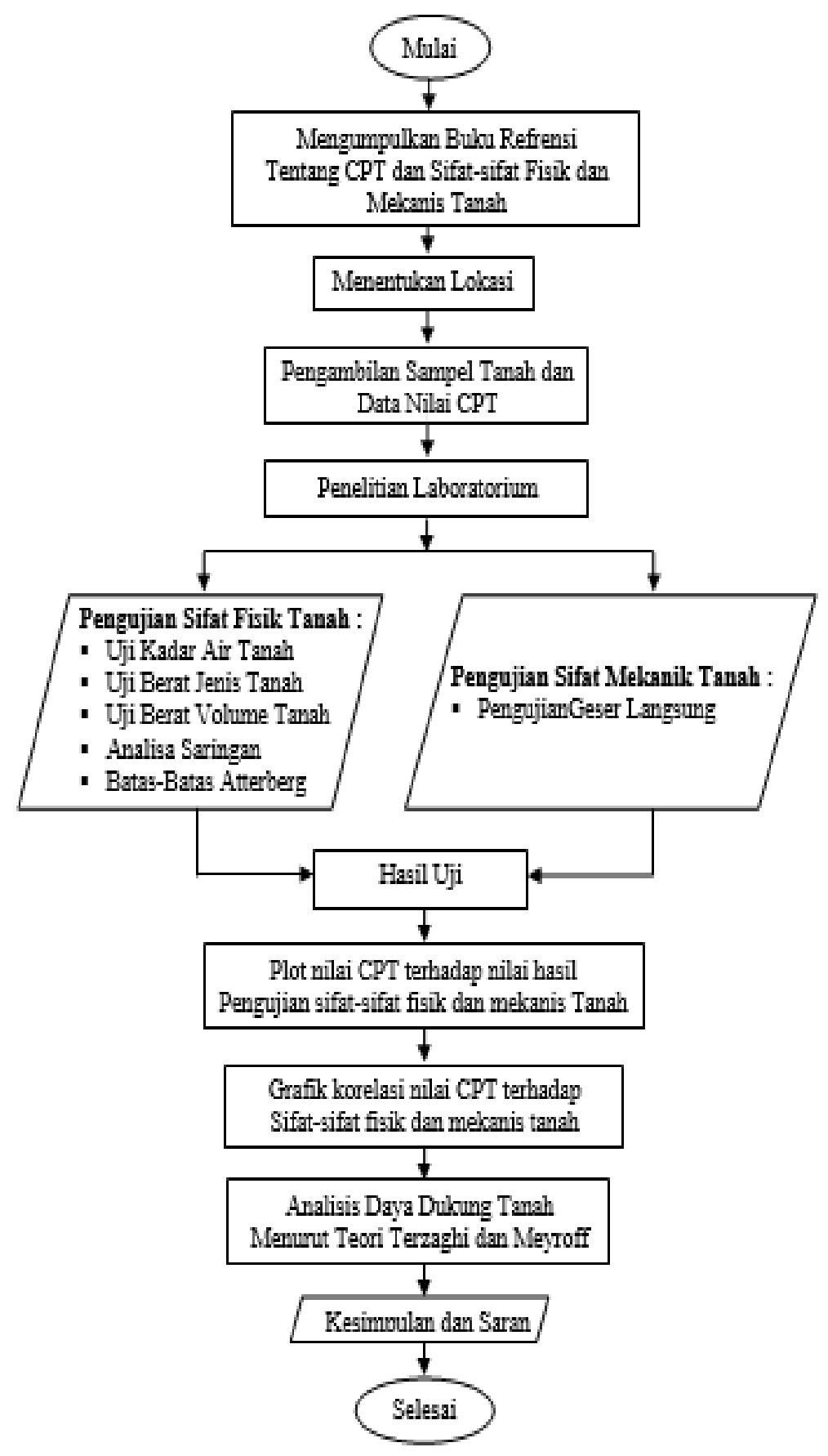

Gambar 1. Bagan Alir Penelitian 


\section{HASIL DAN PEMBAHASAN}

\section{Hasil Pengujian Sifat-Sifat Fisik Tanah}

Tabel 2. Hasil Pemeriksaan Sifat Fisik Tanah

\begin{tabular}{|c|c|c|c|c|c|}
\hline \multirow[t]{3}{*}{ No } & \multirow[t]{3}{*}{ Jenis Pemeriksaan } & \multirow[t]{3}{*}{ Satuan } & \multicolumn{3}{|c|}{ Hasil Pemeriksaan } \\
\hline & & & Tanah & Tanah & Tanah \\
\hline & & & Gambut & Pasir & Lempung \\
\hline 1 & Kadar Air (w) & $\%$ & 391,06 & 18,78 & 34,63 \\
\hline \multirow[t]{6}{*}{2} & Berat Volume & & & & \\
\hline & - $\quad$ Berat Volume isi Tanah & $\mathrm{gr} / \mathrm{cm}^{3}$ & 1,03 & 1,38 & 1,62 \\
\hline & - & $\mathrm{cm}^{3}$ & 482,35 & 2255,13 & 23,24 \\
\hline & Angka Pori (e) & $\%$ & 102,67 & 138,06 & 94,98 \\
\hline & Derajat Kejenuhan (S) & & 1,0 & 1,0 & 0,63 \\
\hline & Porositas (n) & & & & \\
\hline 3 & Berat Jenis (Gs) & & 1,27 & 2,65 & 2,71 \\
\hline \multirow[t]{4}{*}{4} & Batas-batas Atterberg & & & & \\
\hline & - $\quad$ Batas Cair (LL) & $\%$ & - & - & 51,8 \\
\hline & Batas Plastis (PL) & $\%$ & - & - & 37,15 \\
\hline & Indeks Plastisitas (PI) & $\%$ & - & - & 14,65 \\
\hline \multirow[t]{3}{*}{5} & Analisa Saringan & & & & \\
\hline & $\begin{array}{l}-\quad \text { Berat tertahan di } \\
\text { saringan } \quad \text { No.200 }\end{array}$ & $\%$ & 89,60 & 95,98 & 48,66 \\
\hline & - $\quad$ Lolos saringan No.200 & $\%$ & 10,3 & 4,0 & 51,3 \\
\hline \multicolumn{6}{|c|}{$\begin{array}{l}\text { Dari sistem klasifikasi tanah menurut USCS pada tanah gambut kelompok PT } \\
\text { atau Peat (Gambut), muck, dan tanah-tanah lain dengan kandungan organik tinggi, } \\
\text { pada tanah pasir kelompok SP atau Pasir bergradasi buruk, pasir berkerikil, sedikit } \\
\text { atau sama sekali tidak mengandung butiran halus dan pada tanah lempung adalah }\end{array}$} \\
\hline
\end{tabular}

\section{Hasil Pengujian Sifat-Sifat Mekanik Tanah}

Kuat geser tanah diperoleh dari hasil uji percobaan geser langsung (Direct Shear Test) percobaan geser langsung, pengujian ini bertujuan untuk mendapatkan parameter sudut geser dalam $(\varphi)$ dan kohesi $(C)$ yang dilakukan pada tiga jenis tanah yaitu gambut, lempung dan pasir. Berikut adalah tabel pemeriksaan uji geser langsung.

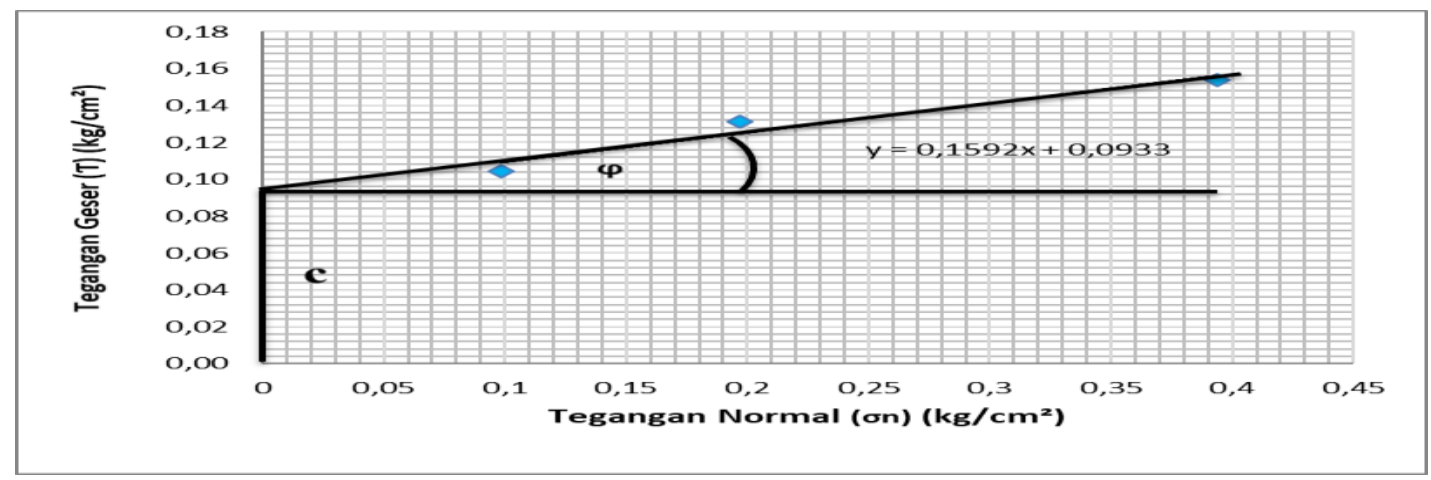

Gambar 2. Grafik Uji Geser Langsung Pada Jenis Tanah Gambut 
Berdasarkan gambar 2. grafik uji geser langsung ( Direct Shear Test) untuk jenis tanah gambut diperoleh nilai kohesi tanah (c) sebesar $0,09 \mathrm{Kg} / \mathrm{cm}^{2}$ dan sudut geser tanah $(\varphi)$ sebesar $9^{0}$. Untuk menghitung nilai kuat geser maka di gunakan rumus sebagai berikut:

$$
\boldsymbol{\tau}=\mathbf{C}+\boldsymbol{\sigma} \operatorname{tg} \phi
$$

Tegangan Normal $(\sigma) \quad=\gamma \cdot \mathrm{h}$

$$
\begin{aligned}
& =0,00103 \mathrm{~kg} / \mathrm{cm}^{3} \times 20 \mathrm{~cm} \\
& =0,021 \mathrm{~kg} / \mathrm{cm}^{2}
\end{aligned}
$$

Jadi kuat geser tanah $(\tau) \quad=\mathrm{C}+\sigma \operatorname{tg} \phi$

$$
\begin{aligned}
& =0,093 \mathrm{Kg} / \mathrm{cm}^{2}+0,021 \tan \left(9^{0}\right) \\
& =0,096 \mathrm{~kg} / \mathrm{cm}^{2}
\end{aligned}
$$

Tabel 3. Rekapitulasi Nilai Kohesi, Tegangan Geser, dan Kuat Geser

\begin{tabular}{cccc}
\hline $\begin{array}{c}\mathbf{t} \\
\text { Jenis Tanah }\end{array}$ & $\begin{array}{c}\text { Nilai } \\
\text { Kohesi }(\mathbf{c})\end{array}$ & $\begin{array}{c}\text { Tegangan } \\
\text { Normal(o) }\end{array}$ & $\begin{array}{c}\text { Nilai Kuat } \\
\text { Geser }(\boldsymbol{\tau})\end{array}$ \\
Tanah Gambut & 0,093 & 0,021 & 0,096 \\
Tanah Lempung & 0,190 & 0,215 & 0,200 \\
Tanah Pasir & 0,067 & 0,150 & 0,230 \\
\hline
\end{tabular}

Hasil dari rekapitulasi nilai kuat geser pada tabel diatas dapat dilihat bahwa tanah gambut memiliki kuat geser yang rendah dikarenakan kohesi pada tanah gambut sangat lemah dibanding dengan tanah lempung, maupun tanah pasir.

Contoh perhitungan daya dukung tanah untuk jenis tanah gambut setelah analisis korelasi menurut teori Terzaghi rumus Keruntuhan Geser Umum Pondasi Menerus sebagai berikut:

$q_{u}=c N_{c}+\gamma D_{f} N_{q}+1 / 2 \gamma B N_{\gamma}$

(c) $=0,168 \mathrm{Kg} / \mathrm{cm}^{2}$

$(\varphi) \quad=14^{\circ}(\mathrm{Nc}=12,11),(\mathrm{Nq}=4,02),(\mathrm{Ny}=1,26)$ Dari tabel 2.14

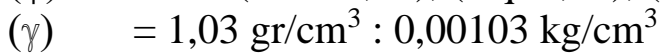

(B) $\quad=2 \mathrm{~m}: 200 \mathrm{~cm}$

(Df) $=3 \mathrm{~m}: 300 \mathrm{~cm}$

Qult $=\mathrm{c} \mathrm{N} \mathrm{N}_{\mathrm{c}}+\gamma \mathrm{D}_{\mathrm{f}} \mathrm{N}_{\mathrm{q}}+1 / 2 \gamma \mathrm{B} \mathrm{N}$

$=0,168 \times 12,11+0,00103 \times 300 \times 4,02+0,5 \times 0,00103 \times 200 \times 1,26$

$=2,034+1,242+0,130$

$=3,4064 \mathrm{~kg} / \mathrm{cm}^{2}$

Daya dukung ijin tanah berdasarkan nilai factor keamanan $(\mathrm{Sf})=3$ jadi didapat nilai $\mathrm{Q}_{\mathrm{ijin}}$ :

$Q_{\text {ijin }}=\frac{Q u l t}{S f}=\frac{3,792}{3}=1,135 \mathrm{~kg} / \mathrm{cm}^{2}$ 
Tabel 4. Rekapitulasi Perhitungan Daya Dukung Tanah qc-CPT Terhadap Kuat Geser Tanah Setelah Analisis korelasi

\begin{tabular}{clc}
\hline Jenis Tanah & & Daya Dukung Tanah \\
\hline & Qult $(\mathrm{kg} / \mathrm{cm} 2)$ & Qijin $(\mathrm{kg} / \mathrm{cm} 2)$ \\
Tanah Gambut & 3,4064 & 1,135 \\
Tanah Lempung & 3,8605 & 1,287 \\
Tanah Pasir & 6,5583 & 2,410 \\
\hline
\end{tabular}

Dari tabel diatas disajikan hasil perhitungan daya dukung dan faktor keamanan dari analisis korelasi antara CPT terhadap Kuat geser tanah, bahwa setelah analisis korelasi daya dukung dan faktor keamanan dari jenis tanah pasir lebih kuat dari pada jenis tanah lainnya, dikarenakan jenis tanah pasir memiliki kohesi yang tinggi.

Tabel 5. Rekapitulasi Perhitungan Daya Dukung Tanah N-SPT Terhadap Kuat Geser Tanah Setelah Analisis korelasi

\begin{tabular}{llc}
\hline Jenis Tanah & \multicolumn{2}{c}{ Daya Dukung Tanah } \\
\hline & Qult $(\mathrm{kg} / \mathrm{cm} 2)$ & Qijin $(\mathrm{kg} / \mathrm{cm} 2)$ \\
Tanah Gambut & 5,7586 & 1,920 \\
Tanah Lempung & 7,9560 & 2,652 \\
Tanah Pasir & 13,8148 & 4,605 \\
\hline
\end{tabular}

Dari tabel diatas disajikan hasil perhitungan daya dukung dan faktor keamanan dari analisis korelasi antara N-SPT terhadap Kuat geser tanah, bahwa setelah analisis korelasi daya dukung dan faktor keamanan dari jenis tanah pasir lebih kuat dari pada jenis tanah lainnya, dikarenakan jenis tanah pasir memiliki kohesi yang tinggi.

\section{Kesimpulan}

\section{PENUTUP}

Dari hasil penelitian ini ada beberapa kesimpulan yaitu sebagai berikut:

1. Berdasarkan data Handboring dari lapangan pada titik diperoleh kedalaman untuk jenis Tanah Gambut 0,2 m; Tanah Pasir $1 \mathrm{~m}$; Tanah Lempung 1,4 m Hasil pengujian sifat fisik tanah diperoleh jenis Tanah Gambut nilai kadar air $(\mathrm{w})=391,06 \%$; berat isi $(\gamma \mathrm{d})=1,03 \mathrm{gr} / \mathrm{cm}^{3}$; berat jenis $(\mathrm{Gs})=1,27$; analisa saringan persentase lolos No. $200=10,3 \%$; dan persentase tertahan No.200 $=89,60 \%$; Tanah Lempung kadar air $(\mathrm{w})=34,36 \%$; berat isi $(\gamma \mathrm{d})=1,62 \mathrm{gr} / \mathrm{cm}^{3}$; berat jenis $(\mathrm{Gs})=2,71$; analisa saringan persentase lolos No.200 $=51,3 \%$; dan persentase tertahan No.200 $=48,66 \%$; batas cair $(\mathrm{LL})=51,85 \%$; batas plastis $(\mathrm{PL})=37,15 \%$; jenis Tanah Pasir nilai kadar air $(\mathrm{w})=18,78 \%$; berat isi $(\gamma \mathrm{d})=1,38$; berat jenis $(\mathrm{Gs})=2,66$; analisa saringan persentase lolos No.200 $=4,0 \%$; dan persentase tertahan $=95,98 \%$. Berdasarkan pemeriksaan $(\mathrm{CPT})$ pada kedalaman 0,0-5,6m didapat nilai tekanan konus (qc) $180 \mathrm{~kg} / \mathrm{cm} 2$ sedangkan nilai N-SPT pada kedalaman 0-30 m didapat N-SPT $=50$

2. Hasil pengujian uji geser langsung Tanah Gambut $(\tau)=0,096$; Tanah Lempung $(\tau)=0,230$; Tanah Pasir $(\tau)=0,200$. Berdasarkan grafik korelasi qcCPT terhadap Kuat geser tanah didapat persamaan $\mathrm{Y}=0,0019 \mathrm{x}+0,2246$ 
dengan nilai koefisien korelasi $(r)=0,741$. Sedangkan Dari grafik korelasi NSPT terhadap kuat geser tanah didapat persamaan $\mathrm{Y}=0,0453 \mathrm{x}+0,0112$ dengan nilai koefisien korelasi $(r)=0,702$. Dari persamaan korelasi yang dijelaskan bahwa untuk nilai koefisien (r) dari qc-CPT dan N-SPT mempunyai hubungan yang sangat kuat.

3. Dari hasil korelasi antara qc-CPT dengan kuat geser tanah diperoleh nilai daya dukung tanah tanah gambut Qult $=3,4064 \mathrm{~kg} / \mathrm{cm}^{2}$; Qijin $=1,135 \mathrm{~kg} / \mathrm{cm}^{2}$; Tanah Lempung Qult $=3,8605 \mathrm{~kg} / \mathrm{cm}^{2}$; Qijin $=1,287 \mathrm{~kg} / \mathrm{cm}^{2}$; Tanah Pasir Qult $=6,5583 \mathrm{~kg} / \mathrm{cm}^{2}$; Qijin $=2,410 \mathrm{~kg} / \mathrm{cm}^{2}$. Sedangkan nilai korelasi antara N-SPT dengan kuat geser tanah diperoleh nilai daya dukung tanah Tanah Gambut Qult $=5,7586 \mathrm{~kg} / \mathrm{cm}^{2}$; Qijin $=1,920 \mathrm{~kg} / \mathrm{cm}^{2}$; Tanah Lempung Qult $=7,9560 \mathrm{~kg} / \mathrm{cm}^{2}$; Qijin= 2,652 kg/cm ${ }^{2}$; tanah pasir Qult=13,8148 $\mathrm{kg} / \mathrm{cm}^{2}$; Qijin=4,605 kg/cm².

\section{Saran}

1. Setiap daerah memiliki sifat fisik tanah dasar pada yang berbeda, oleh karena itu perlu dilakukan pengujian sifat fisik tanah.

2. Disarankan pada penelitian selanjutnya agar menggunakan data/ sampel dan titik lebih banyak dengan menggunakan data terbaru sehingga diperoleh hasil perbandingan yang akurat.

3. Untuk pembacaan arloji ukur (dial) supaya diperhatikan dengan seksama agar mendapatkan hasil yang lebih akurat.

4. Ketelitian dalam penelitian data/ sampel yang digunakan harus diperhatikan dengan baik.

\section{DAFTAR PUSTAKA}

1. Ardiansyah Roni. 2016. Korelasi hasil percobaan CPT dengan SPT pada lokasi pusat kota Pekanbaru.

2. Bowles, Joseph E. 1991. "Analisis Desain dan Pondasi". Jakarta, Erlangga, Jakarta.

3. Das, B. M. 1993. "Mekanika Tanah. (Prinsip-prinsip Rekayasa Geoteknis)". Jilid, I Penerbit Erlangga, Jakarta.

4. Feriyansyah, H. 2013. "Analisis Stabilitas Lereng (Studi Kasus di Kelurahan Sumur Batu Bandar Lampung)". Skripsi Fakultas Teknik Universitas Lampung.

5. Hardiyatmo, Hary Christday. 1992 . “Mekanika Tanah I'. PT. Gramedia Pustaka Utama Jakarta.

6. Hardiyatmo, Hary Christday. 2002. "Mekanika Tanah II”. Gramedia Pustaka Utama Jakarta.

7. United Soul Classification System, 1952. "U.S Standart Sieve Numbers".

8. Vidayanti Desiana. Pintor T Simatupang. 2013. Korelasi Nilai N-SPT dengan Parameter Kuat Geser tanah wilayah Jakarta dan sekitarnya (133g). 